\title{
Combined Natural Convection and Thermal Radiation in an Inclined Cubical Cavity with a Rectangular Pins Attached to Its Active Wall
}

\author{
Z. Sert ${ }^{1}$, M. Tekkalmaz ${ }^{1}$, C. Timuralp ${ }^{1}$ \\ ${ }^{1}$ Departement of Mechanical Engineering,Eskisehir Osmangazi University
}

\begin{tabular}{l}
\hline \hline Article Info \\
\hline Article history: \\
Received May $30^{\text {th }}, 2017$ \\
Revised Aug $20^{\text {th }}, 2017$ \\
Accepted Oct $18^{\text {th }}, 2017$
\end{tabular}

\section{Keyword:}

Heat transfer

Inclined cubic enclosure

Natural convection

$\mathrm{S} 2 \mathrm{~S}$ radiation

\begin{abstract}
Three dimensional combined natural convection and thermal radiation in an inclined cubic enclosure with pins attached to the active wall is investigated numerically. The vertical opposing walls are heated and cooled while the other walls are assumed to be adiabatic. The governing flow, momentum equations and the radiative transfer are solved using Fluent ${ }^{\circledR} 6.3$ CFD software. In the discretization of the convection terms, the second order upwind scheme and for the solution algorithm SIMPLE is used. The cubic enclosure is filled with air and the flow is considered to be laminar. The properties of air are assumed to be constant except for the density variation for which the Boussinesq approximation is used. The surface to surface (S2S) heat model is used as the radiation transfer model. The computations are performed for Rayleigh number in the range $10^{3} \leq \mathrm{Ra} \leq 10^{6}$ and for the surface emissivity $(\varepsilon) 0 \leq \varepsilon \leq 1$ while the inclination angle is varied $0^{\circ} \leq \varphi \leq 75^{\circ}$. The mean Nusselt number for convection and radiation transfer were evaluated as a function of Rayleigh number, emissivity and inclination angle and for some cases, the fluid flow and the temperature distributions were analyzed. The results showed that the mean total and radiative Nusselt number increases monotonically with increasing Ra number and the surface emissivity.
\end{abstract}

\section{Corresponding Author:}

C. Timuralp,

Department of Mechanical Engineering,

Eskisehir Osmangazi University,

Bati-Meselik 26480 Eskisehir, Turkey.

Email: cisil@ogu.edu.tr

\section{Introduction}

The natural convection and thermal radiation heat transfer in fluid filled cavities has received considerable attention in recent years due to its relation to the thermal performance of engineering applications such as cooling of electronic components, electrical boxes, solar energy collector designs and heat exchanger designs so on. Thus, the combined characteristic of natural convection and thermal radiation heat transfer are more important.

Baig and Masood [1], numerically studied the two-dimensional natural convection phenomena in a rotating and differentially heated square enclosure. The results are presented in terms of the Rayleigh, Taylor numbers and rotational Rayleigh number. It is found that a significant enhancement in heat transfer can be achieved due to rotational effects. Rahman and Sharif [2], numerically investigated laminar natural convection in rectangular enclosures of different aspect ratios and at various angles of inclination. At certain inclinations the local heat flux ratios increased initially and then decreased. Jin et al. [3], investigated the effects of rotation on natural convection cooling in a rectangular cavity. It is observed that rotation reduced oscillation in Nusselt number and improved heat transfer in the weak stages. Cheng and Liu [4], performed the effects of cavity inclination, Richardson number and the aspect ratio on the mixed convection heat transfer in two-dimensional 
cavity flows. The results indicated that in a forced convection dominated regime, the increase of inclination angle does not affect the flow structures and heat transfer; but for $\mathrm{Ri}=100$ it has a significant impact on the flow and thermal fields. Saleh and Hashim [5], studied the problem of conjugate convection heat transfer in a rotating square enclosure numerically. They presented the results for flow fields and heat transfer performance of rotating enclosure in graphical forms.

Impacts of inclination in natural convection was studied three-dimensional enclosures. Li and Tong [6], carried out natural convective heat transfer in the inclined rectangular cavities using three-dimensional numerical simulations and experimental measurements. With the increase in the aspect ratio and the cavity inclination angle resulted in accelerated natural convection and enhanced the convective heat transfer in the cavity. Awasarmol and Pise [7], experimentally investigated natural convection heat transfer enhancement of perforated rectangular fin array at different angles of inclination. They observed that the perforation of fins enhances the heat transfer dissipation rates and the optimum perforation diameter depends the inclination angle.

The thermal radiation heat transfer plays an important role in cases where it cannot be ignored or neglected. Ramesh and Venkateshan [8], experimentally examined the effect of surface radiation on the natural convection in a square 2D enclosure. Correlations for convective Nusselt number, radiative Nusselt number, and total Nusselt number are given in terms of Grashof number. Bouali et.al [9], analyzed the radiation-natural convection interactions in an inclined rectangular enclosure with and without inner body numerically. The results showed that the inclination angle affects the isotherms and streamline values for both cavities and radiation heat transfer increases the average Nusselt number without body case. The radiation-natural convection heat transfer in inclined rectangular enclosures containing multiple partitions was investigated by Rabhiet. al. [10]. The results showed that the radiation increases the Nusselt number significantly. Nouanegueet. al. [11], investigated the effect of the surface radiation on the conjugate heat transfer by natural convection and conduction in an inclined square enclosure. They observed that the radiation affected the flow and temperature fields. Interaction effects between laminar natural convection and surface radiation in tilted square and shallow enclosures have been determined by Vivek et.al. [12]. They found that interaction effects are much stronger in shallow enclosures compared to square enclosures.

The present study investigates numerically combined laminar natural convection and thermal radiation heat transfer in an inclined cubic enclosure. The enclosure is assumed to be cubical in form. The enclosure is heated on one vertical wall and cooled from an opposite wall, while the other walls are adiabatic.

\section{Mathematical Formulation}

The studied geometry and coordinate system of the considered enclosure in the present study are depicted in Figure 1. Pins with dimensions are $(0.1 \mathrm{H} \times 0.1 \mathrm{H} \times 0.6 \mathrm{H})$ are attached to hot wall of the cubical enclosure whose dimensions are $\mathrm{H} \times \mathrm{H} \times \mathrm{H}$. The hot wall (with the pins) and cold wall are isothermal while the side walls are adiabatic. The enclosure is filled with air $(\mathrm{Pr}=0.71)$.

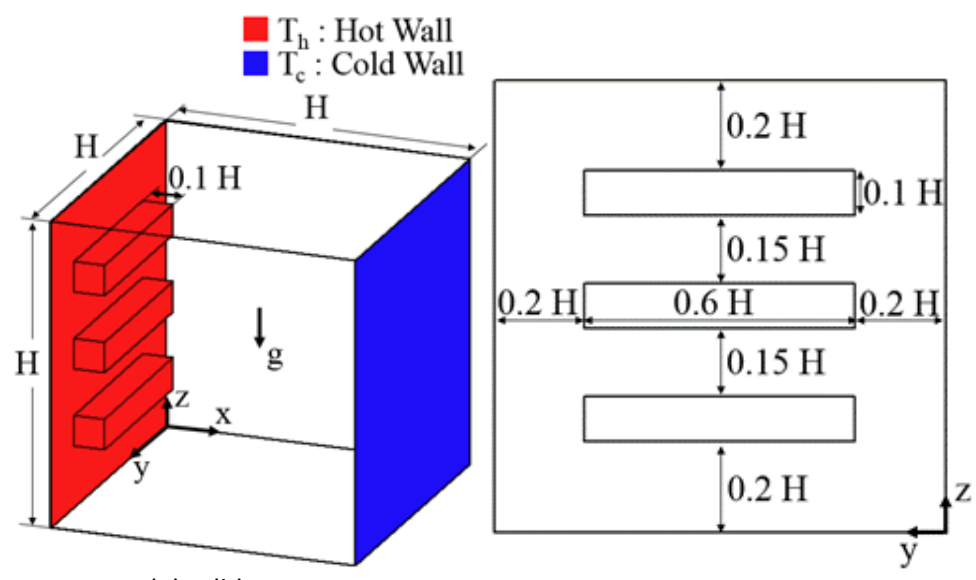

(a) (b)

Figure 1. Schematic diagram of the computational domain. a) isometric, b) front view. 
The governing continuity, flow and energy equations are given respectively,

for the continuity,

$$
\frac{\partial u}{\partial x}+\frac{\partial v}{\partial y}+\frac{\partial w}{\partial z}=0
$$

for the $\mathrm{x}, \mathrm{y}$ and $\mathrm{z}$ momentum equations

$$
\begin{gathered}
u \frac{\partial u}{\partial x}+v \frac{\partial u}{\partial y}+w \frac{\partial u}{\partial z}=-\frac{1}{\rho} \frac{\partial P}{\partial x}+v\left[\frac{\partial^{2} u}{\partial x^{2}}+\frac{\partial^{2} u}{\partial y^{2}}+\frac{\partial^{2} u}{\partial z^{2}}\right] \\
u \frac{\partial v}{\partial x}+v \frac{\partial v}{\partial y}+w \frac{\partial v}{\partial z}=-\frac{1}{\rho} \frac{\partial P}{\partial y}+v\left[\frac{\partial^{2} v}{\partial x^{2}}+\frac{\partial^{2} v}{\partial y^{2}}+\frac{\partial^{2} v}{\partial z^{2}}\right] \\
u \frac{\partial w}{\partial x}+v \frac{\partial w}{\partial y}+w \frac{\partial w}{\partial z}=-\frac{1}{\rho} \frac{\partial P}{\partial z}+v\left[\frac{\partial^{2} w}{\partial x^{2}}+\frac{\partial^{2} w}{\partial y^{2}}+\frac{\partial^{2} w}{\partial z^{2}}\right]-g \beta\left(T-T_{0}\right)
\end{gathered}
$$

for the energy

$$
\mathrm{u} \frac{\partial \mathrm{T}}{\partial \mathrm{x}}+\mathrm{v} \frac{\partial \mathrm{T}}{\partial \mathrm{y}}+\mathrm{w} \frac{\partial \mathrm{T}}{\partial \mathrm{z}}=\alpha\left[\frac{\partial^{2} \mathrm{~T}}{\partial \mathrm{x}^{2}}+\frac{\partial^{2} \mathrm{~T}}{\partial \mathrm{y}^{2}}+\frac{\partial^{2} \mathrm{~T}}{\partial \mathrm{z}^{2}}\right]
$$

where $u, v, w$ is the velocity, is the density, $\rho$ is the pressure, $v$ is the kinematic viscosity, $\beta$ is the thermal expansion coefficient, $\mathrm{T}$ is the temperature, $\alpha$ is the thermal diffusivity. Prandtl and Rayleigh numbers are defined asPr $=v / \alpha$ and $\mathrm{Ra}=\mathrm{g} \beta\left(\mathrm{T}_{\mathrm{h}}-\mathrm{T}_{\mathrm{c}}\right) \mathrm{H}^{3} / v \alpha$ respectively.

The boundary conditions can be written as follows:

a) At the cold wall

$$
\mathrm{T}=\mathrm{T}_{\mathrm{c}}, \mathrm{u}=\mathrm{v}=\mathrm{w}=0
$$

b) At the hot wall

$$
\mathrm{T}=\mathrm{T}_{\mathrm{h}}, \mathrm{u}=\mathrm{v}=\mathrm{w}=0
$$

c) At the insulated walls (The adiabatic walls)

$$
\mathrm{q}_{\mathrm{c}}+\mathrm{q}_{\mathrm{r}}=0 \text { or }-\mathrm{k} \frac{\partial \mathrm{T}}{\partial \mathrm{n}}+\mathrm{q}_{\mathrm{r}}=0
$$

where $\mathrm{n}$ is the perpendicular direction to pertinent wall, $\mathrm{q}_{\mathrm{r}}$ is also the radiation heat flux on the corresponding insulated wall.

The mean total Nusselt number for cold wall is calculated by,

$$
\mathrm{Nu}_{\mathrm{t}}=\mathrm{Nu}_{c}+\mathrm{Nu}_{\mathrm{r}}=\frac{\mathrm{q}_{c}+\mathrm{q}_{\mathrm{r}}}{\mathrm{k}\left(\mathrm{T}_{\mathrm{h}}-\mathrm{T}_{\mathrm{c}}\right) / \mathrm{H}}
$$

where $\mathrm{q}_{c}$ convection heat flux.

\section{Numerical Methodology And Validation Of The Numerical Code}


In this study, the continuity, momentum and the energy equations are solved using the commercially available code Fluent ${ }^{\circledR}$ 6.3. The flow field in the computational domain is solved using SIMPLE algorithm with the second order upwind scheme. The convergence criterion for the inner iterations was $10^{-5}$ for the continuity, momentum and energy equations while under-relaxation factors are set to the default values in the program. The analysis is performed for the Rayleigh number which is varied between $10^{3}$ and $10^{6}$ while the emissivity is $0 \leq \varepsilon \leq 1$. The inclination angle is taken $0^{\circ}, 15^{\circ}, 30^{\circ}, 60^{\circ}$ and $75^{\circ}$ respectively.

The present numerical scheme was validated against various numerical results available in the literature. To determine the grid independent solutions, a comparison of the mean convective Nusselt numbers (or the mean total Nu numbers - pure natural convection $(\varepsilon=0)$ ) with the published results for a bare cubic enclosure (with no pins) for various Rayleigh numbers is provided in Table 1.

The variation of the mean total Nusselt number at cold wall for various grids are shown in Figure 2. For verification of the numerical solutions validations with solved problems in the literature have been carried out. The independence of the solution with respect to the grid size has been examined for different Rayleigh numbers, $\varepsilon=1$ and $\varphi=0^{\circ}$. Three grid configurations consisting of $50 \times 50 \times 50,80 \times 80 \times 80$ and $100 \times 100 \times 100$ have been used. As can be observed from the Figure 2, a uniform $80 \times 80 \times 80$ grid was found to be sufficiently fine for the numerical analysis.

Table 1. Effect of the grid size on $\mathrm{Nu}_{\mathrm{t}}$ for the bare cubic enclosure (without no pins)

\begin{tabular}{cccccc}
\hline & \multicolumn{5}{c}{$\mathrm{Nu}$} \\
\cline { 4 - 6 } $\mathrm{Ra}$ & \begin{tabular}{c} 
Colomer \\
\cline { 4 - 6 }
\end{tabular} & \begin{tabular}{c} 
Böcü and \\
\cline { 4 - 6 }
\end{tabular} & $50 \times 50 \times 50$ & $80 \times 80 \times 80$ & $100 \times 100 \times 100$ \\
\hline $10^{3}$ & 1.055 & 1.0706 & 1.071 & 1.071 & 1.071 \\
\hline $10^{4}$ & 2.030 & 2.0575 & 2.064 & 2.059 & 2.058 \\
\hline $10^{5}$ & 4.334 & 4.3598 & 4.399 & 4.363 & 4.354 \\
\hline $10^{6}$ & 8.862 & 8.7945 & 9.038 & 8.801 & 8.744 \\
\hline
\end{tabular}

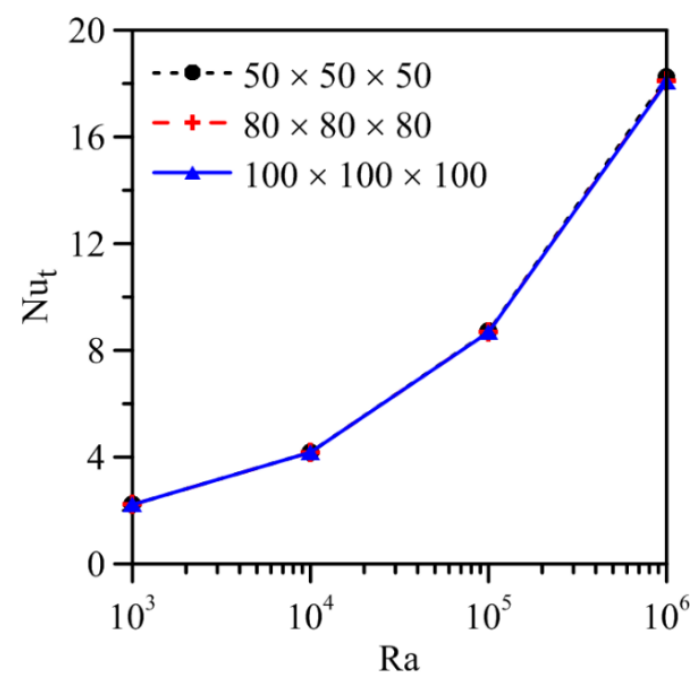

Figure 2. Variation of the mean total Nusselt number at cold wall with mesh parameters.

\section{Results And Discussions}

The presented results are generated for different dimensionless groups, such as the Rayleigh number $\left(10^{3} \leq \mathrm{Ra}\right.$ $\left.\leq 10^{6}\right)$, the surface emissivity $(0 \leq \varepsilon \leq 1)$ and the inclination angle of cubical enclosure $\left(0^{\circ} \leq \varphi \leq 75^{\circ}\right)$. The enclosure is filled with air where constant Pr number is kept at 0.71 . The predicted hydrodynamic and thermal fields variables are depicted through the streamlines, the temperature iso-surfaces, and the corresponding velocity and temperature profiles. The mean total, radiative and convective Nusselt number is also represented in order 
to supply useful information about the influence of each parameter, quoted above, on heat transfer enhancement.

Figure 3 shows the effects of $\mathrm{Ra}=10^{4}, 10^{5}, 10^{6}$, on isotherms and path lines (colored by temperature) as well as on temperature field (along $\mathrm{x} / \mathrm{H}=0.05$ and $\mathrm{z} / \mathrm{H}=0.1$ planes) for the present configuration at $\varepsilon=0.75, \varphi=0^{\circ}$. The flow for all Ra numbers in this work have been affected by the buoyancy force. For $\mathrm{Ra}=10^{4}$, the buoyancy force is not so significant. However, when Ra number is increased to $10^{5}$ and $10^{6}$, the buoyance force becomes more pronounced, and the difference caused by the inhomogeneity of medium declines. While increased Rayleigh number, as evidenced by the value of path lines, the circulation becomes stronger. Thus, more energy is transported into the medium from the hot wall. When examined the temperature fields (along $\mathrm{x} / \mathrm{H}=0.05$ and $\mathrm{z} / \mathrm{H}=0.1$ planes) for high $\mathrm{Ra}$ numbers, the temperature gradients around the pins increase. Hence the heat flux augments.
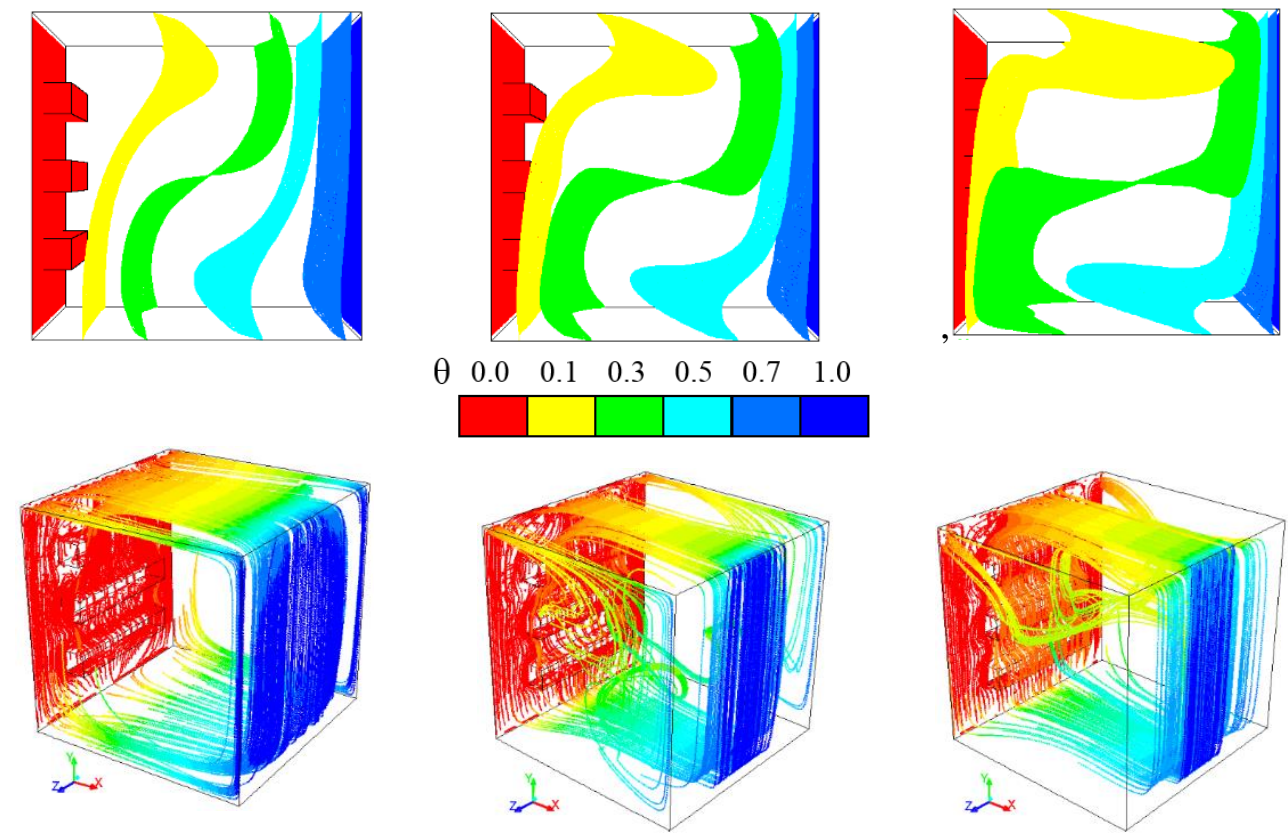

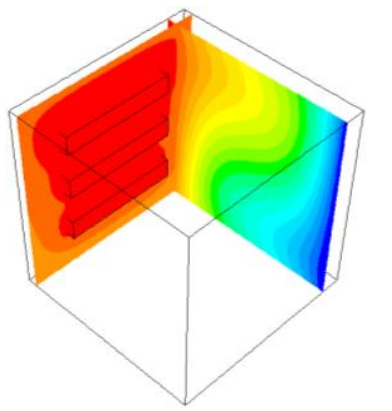

(a)

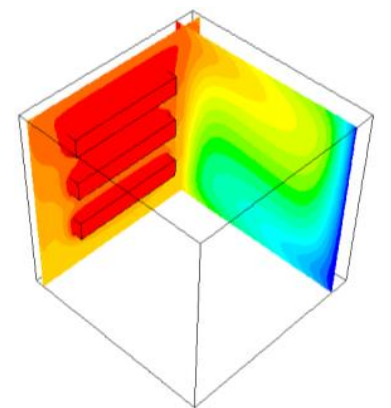

(b)

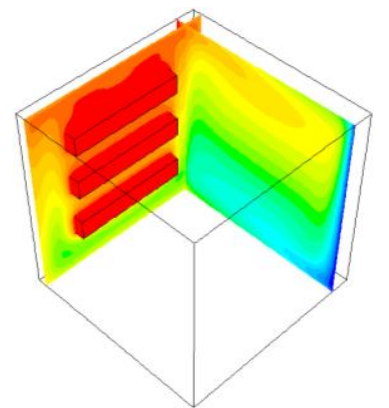

(c)

Figure 3. The effect of Rayleigh number on isothermal surfaces (top), path lines (colored by temperature) (middle) and temperature field along $\mathrm{x} / \mathrm{H}=0.05$ and $\mathrm{z} / \mathrm{H}=0.1$ planes (below) for $\varepsilon=0.75, \varphi=0^{\circ}$ and $\mathrm{a}$ ) $\mathrm{Ra}=10^{4}, \mathrm{~b}$ )

$$
\mathrm{Ra}=10^{5} \text {, c) } \mathrm{Ra}=10^{6} \text {. }
$$

Figure 4 shows a three-dimensional velocity and temperature fields for different values of the inclination angle $\left(\varphi=0^{\circ}, 30^{\circ}\right.$ and $\left.60^{\circ}\right)$ at $\varepsilon=0.5$ and $\mathrm{Ra}=10^{5}$. The fluid flow patterns are reported using pathlines graphs, whereas the temperature fields are shown using isotherms graphs. The isotherms and streamlines are concentrated on the surface of hot and cold wall. Further, it is observed that the nature of the streamlines and isotherms do not change significantly as the angle of inclination changes. When the enclosure has an inclination angle of $30^{\circ}$, the velocity magnitude of the airflow is larger values than those of the flow when the enclosure is not inclined. 
The variation of the mean total, radiative and convective Nusselt number with the Rayleigh number for several surface emissivities is briefly sketched in Figure 5. Independently of surface radiation, the mean all $\mathrm{Nu}$ numbers increases with increasing Ra number. Moreover, the surface thermal radiation in the heat transfer problems plays an important role. The mean total and radiative Nusselt number increase considerably with increasing the surface emissivity. In comparison with pure natural convection, when the surface emissivity is existed, the total and radiative heat flux increase. The mean total $\mathrm{Nu}$ number is two times higher when the surfaces are black $(\varepsilon=1)$ only in case of pure natural convection. But with the effect of surface radiation, the mean convective $\mathrm{Nu}$ number changes. With increasing surface radiation, at high Ra numbers, the mean convective $\mathrm{Nu}$ number decrease modestly.
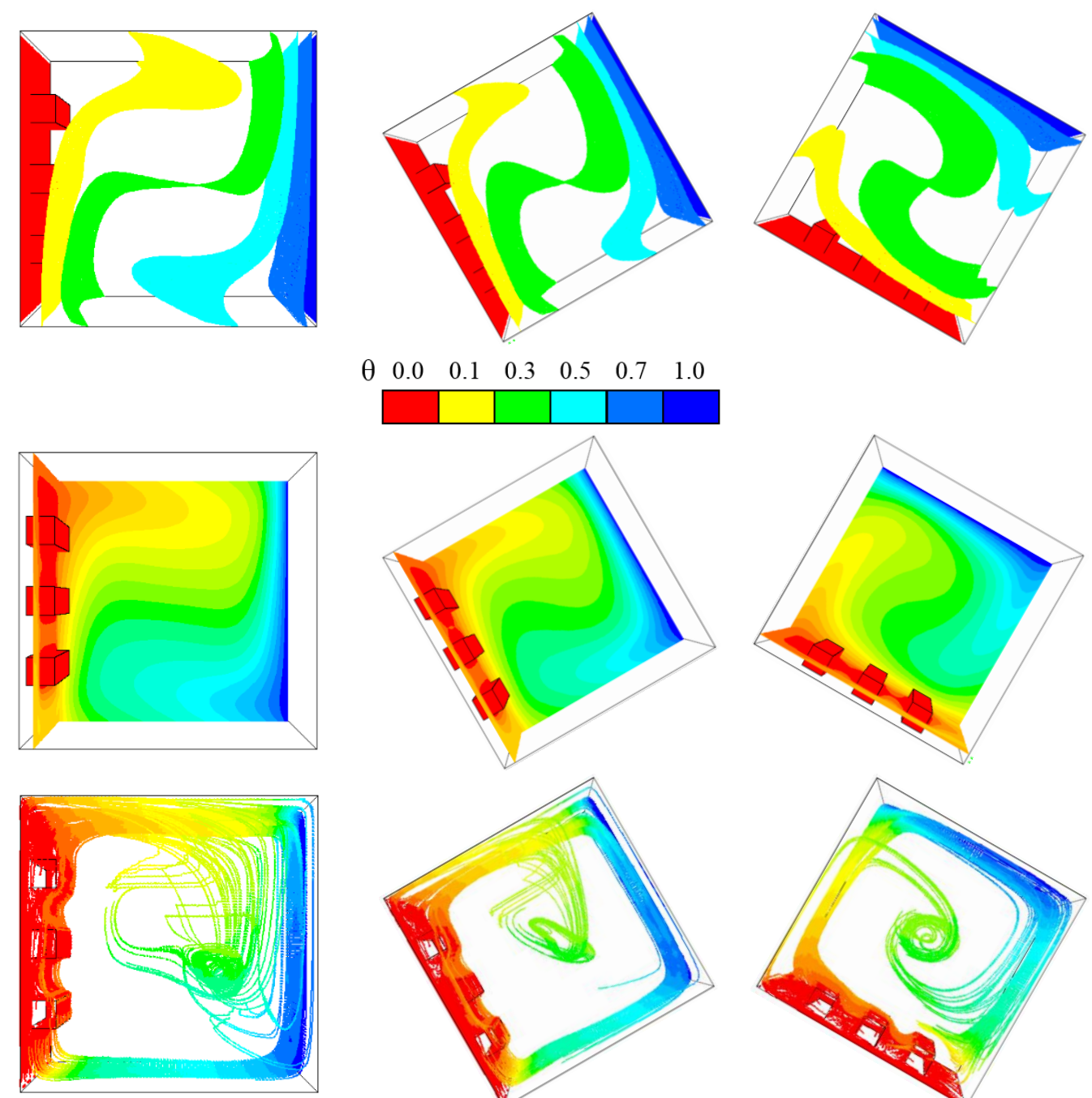

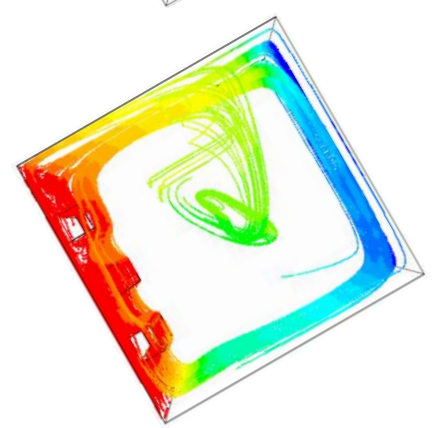

(b)

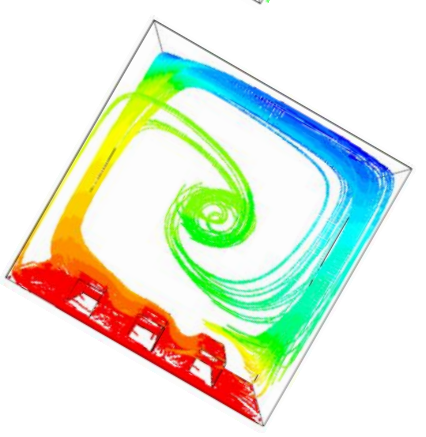

(c)

Figure 4. The effect of inclination angle on isothermal surfaces (top), temperature field along $\mathrm{x} / \mathrm{H}=0.05$ and $\mathrm{z} / \mathrm{H}=0.1$ planes (middle) and path lines (colored by temperature) (below) for $\varepsilon=0.5, \mathrm{Ra}=10^{5}$ and a) $\varphi=0^{\circ}, \mathrm{b}$ ) $\left.\varphi=30^{\circ}, \mathrm{c}\right) \varphi=60^{\circ}$.

The effect of inclination angle and the surface emissivity on the mean total Nusselt number is depicted in Figure 6. The analysis has been conducted in a wide range of the inclination angle: $\varphi=0^{\circ}, 15^{\circ}, 30^{\circ}, 45^{\circ}, 60^{\circ}$ and $75^{\circ}$. It is also observed that the heat transfer increases at first and then decreases with increasing inclination of the enclosure, therefore the total mean Nusselt number reaches its maximum at a specific inclination angle where the maximum heat transfer is detected at about $\varphi=30^{\circ}$. Within the three surface emissivities provided, the relationship between the inclination angle of the enclosure and the mean total $\mathrm{Nu}$ number shows similar characteristics. 
Figure 7 shows the mean total $\mathrm{Nu}$ numbers versus Ra numbers for cubical enclosure with rectangular pins and bare cubical enclosure. As shown in Figure 7, the slope of the mean total Nu numbers versus Ra is greater for the enclosure with rectangular pins compared with bare enclosure, which means a considerable enhancement of heat transfer due the addition of pins. For high surface emissivity, relative difference is nearly $\% 10-6.5$, but also for low surface emissivity, relative difference is nearly \%3-4.5.

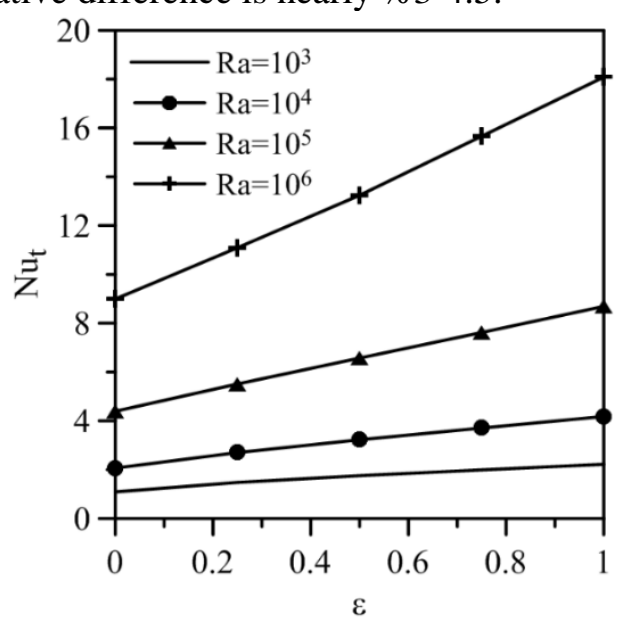

(a)

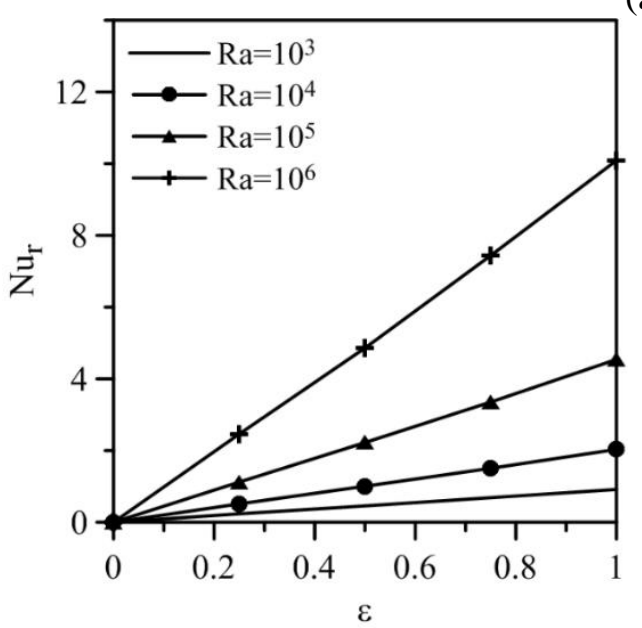

(b)

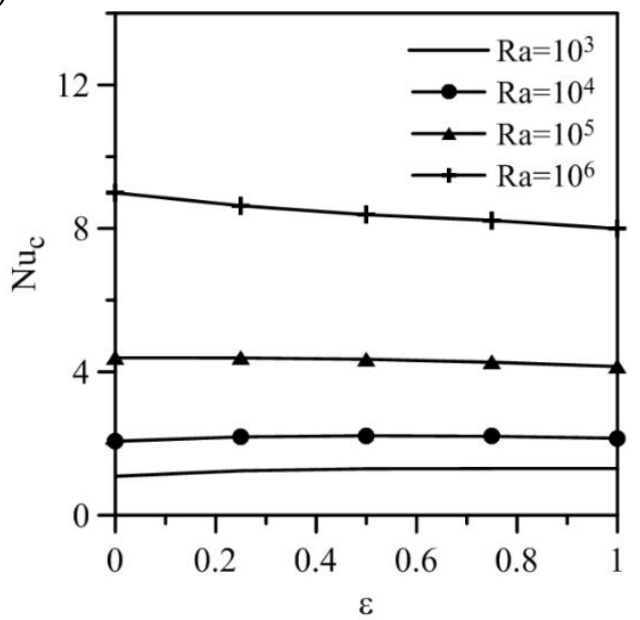

(c)

Figure 5. Variation of the mean a) total, b) radiative and c) convective Nusselt number with the surface emissivity and Rayleigh number at $\varphi=0^{\circ}$.

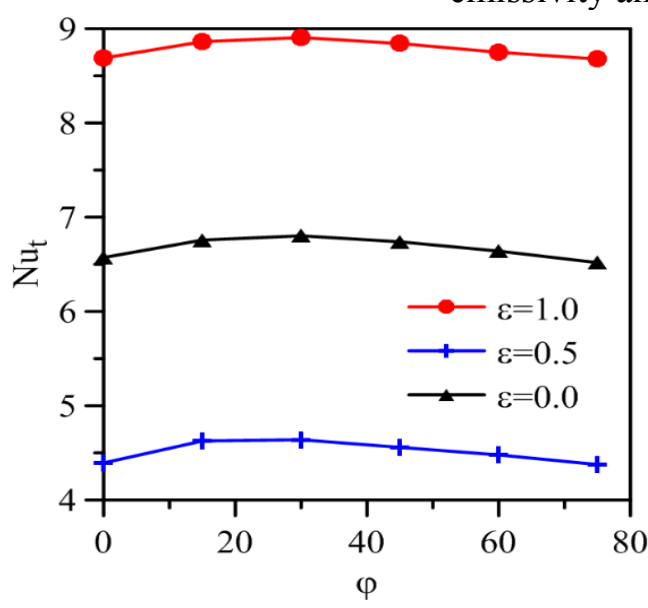

Figure 6. Variation of the mean total Nusselt number with inclination angle for different surface emissivity at $\mathrm{Ra}=10^{5}$.

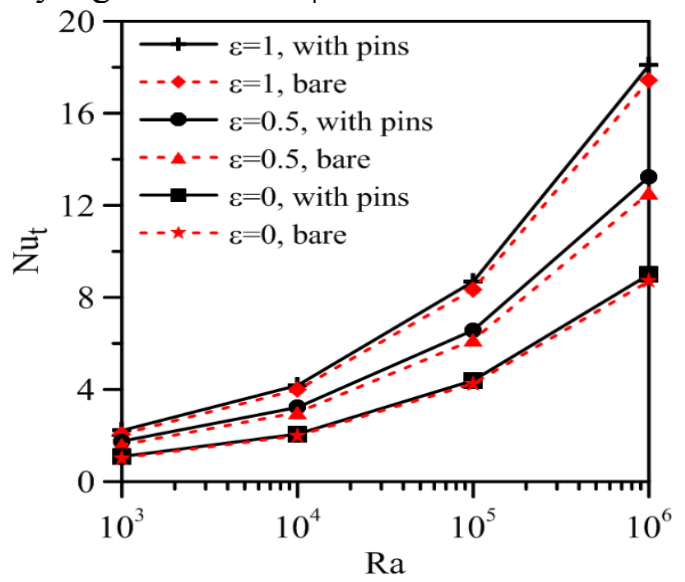

Figure 7. Comparison of the mean Nu number in bare and with pins cubic enclosure at $\varphi=0^{\circ}$. 


\section{Conclusion}

Based on these results, the following results was obtained:

-Independently of surface radiation, the mean total, radiative and convective Nusselt number increases monotonically with increasing Rayleigh number and a major part of the enclosure is employed by the flow, especially at high Rayleigh numbers.

-The mean total and radiative Nusselt number increase considerably with increasing the surface emissivity.

-The mean total and convective Nusselt number increases first then decreases, with increasing inclination of the cubic enclosure for all cases.

-The presence of the rectangular pins has significant effects on heat and flow characteristics in the cubic enclosure.

\section{References}

[1]. M. F. Baigand A. Masood, "Natural convection in a two-dimensional differentially heated square enclosure undergoing rotation", Numerical Heat Transfer Part A: Applications, vol. 40, pp. 181-202, 2001.

[2]. M. Rahmanand M. A. R. Sharif, "Numerical study of laminar natural convection in inclined rectangular enclosures of various aspect ratios", Numerical Heat Transfer Part A, vol. 44, pp. 355-373, 2003.

[3]. L.F. Jin, K.W. Tou, C.P. Tso, "Effects of rotation on natural cooling from three rows of heat sources in a rectangular cavity", International Journal of Heat and Mass Transfer, vol. 48, pp. 3982-3994, 2005.

[4]. T.S. Cheng and W.H. Liu, "Effects of cavity inclination on mixed convection heat transfer in lid-driven cavity flows", Computers \& Fluids, vol.100, pp.108-122, 2014.

[5]. H. Saleh and I. Hashim, "Conjugate natural convection heat transfer in a rotating enclosure", Journal of Applied Fluid Mechanics, vol. 9, pp. 945-955, 2016.

[6]. H. Li, S. Tong, "Natural convective heat transfer in the inclined rectangular cavities with low width-toheight ratios", International Journal of Heat and Mass Transfer, vol. 93, pp. 398-407, 2016.

[7]. U. V. Awasarmol and A. T. Pise, "An experimental investigation of natural convection heat transfer enhancement from perforated rectangular fins array at different inclinations", Experimental Thermal and Fluid Science, vol. 68, pp. 145-154, 2015.

[8]. N. Ramesh and S.P. Venkateshan, "Effect of surface radiation on natural convection in a square enclosure", Journal of Thermophysics and Heat Transfer, vol. 13, pp. 299-301, 1999.

[9]. H. Bouali, A. Mezrhab, H. Amaoui, M. Bouzidi, "Radiation-natural heat transfer in an inclined rectangular enclosure”, International Journal of Thermal Sciences, vol. 45, pp. 553-566, 2006.

[10]. M. Rabhi, H. Bouali, A. Mezrhab, "Radiation-natural convection heat transfer in inclined rectangular enclosures with multiple partitions", Energy Conversion and Management, vol. 49, pp. 1228-1236, 2008.

[11]. H.F. Nouanegue, A. Muftuoglu, E. Bilgen, "Heat transfer by natural convection, conduction and radiation in an inclined square enclosure bounded with a solid wall", International Journal of Thermal Sciences, vol. 48, pp. 871-880, 2009.

[12]. V. Vivek, A.K. Sharma, C. Balaji, "Interaction effects between laminar natural convection and surface radiation in tilted square and shallow enclosures",International Journal of Thermal Sciences,vol. 60, pp.7084, 2012.

[13] G. Colomer, M. Costa, R. Consul, A. Oliva, "Three dimensional numerical simulation of convection and radiation in a differentially heated cavity using the discrete ordinates method", International Journal of Heat and Mass Transfer, vol. 47, pp. 257-269, 2004.

[14] Z. Böcü and Z. Altaç, "Laminar natural convection heat transfer and air flow in three-dimensional rectangular enclosures with pin arrays attached to hot wall", Applied Thermal Engineering, vol. 31, pp. 31893195, 2011. 